\title{
Soy Isoflavones and Breast Cancer Risk: A Meta-analysis
}

\author{
IOANNIS BOUTAS ${ }^{1}$, ADAMANTIA KONTOGEORGI ${ }^{1}$, \\ CONSTANTINE DIMITRAKAKIS ${ }^{2}$ and SOPHIA N. KALANTARIDOU ${ }^{1}$ \\ ${ }^{1}$ Third Department of Obstetrics and Gynecology, \\ National and Kapodistrian University of Athens, Attikon Hospital, Athens, Greece; \\ ${ }^{2}$ First Department of Obstetrics and Gynecology, \\ National and Kapodistrian University of Athens, Alexandra Hospital, Athens, Greece
}

\begin{abstract}
Background/Aim: Soy contains genistein and daidzein isoflavones. Isoflavones are phytoestrogens, with a similarity in structure to human 17- $\beta$ estradiol hormone. They imitate the action of estrogen on organs by binding and activating estrogen receptors. Numerous studies have examined the relationship between soy consumption and breast cancer but not the amount of consumption itself. We performed a systematic review of the literature in order to determine whether the amount of soy and isoflavones consumed has a positive effect in pre- and post-menopausal women. Materials and Methods: Data gathering was performed following PRISMA guidelines. Narrowing down the result set for all relevant data was performed via title, abstract, full-text evaluation and the snowball procedure. The selected articles had all relevant data extracted. Analysis of the data was performed using Cochrane's Review Manager statistical analysis tool in order to draw conclusions regarding the positive effect for the amount of soy and isoflavones consumed. Results: Significant results were found when statistically analyzing data from prospective studies which compared soy isoflavones consumption, breast cancer risk and occurrence. The data were indicative of a clear inverse correlation between the amount of isoflavones consumed and breast cancer occurrence in pre- and postmenopausal women. Conclusion: The consumption of soy isoflavones can reduce the risk of breast cancer in premenopausal and post-menopausal women.
\end{abstract}

This article is freely accessible online.

Correspondence to: Dr. Ioannis Boutas (ORCID: 0000-0002-36674520), Attikon University Hospital, Rimini 1, 12462, Chaidari, Athens, Greece. Mobile: +30 6936829726, e-mail: ioannis.boutas@gmail.com

Key Words: Soy, isoflavones, breast cancer risk, meta-analysis, review.
Breast cancer is one of the most common forms of cancer in females (1). During the past couple of decades, there has been an emerging belief that dietary interventions can significantly reduce the risk of development of breast cancer and the mortality rate of the disease $(2,3)$. One of these nutritional interventions is soy and soy isoflavones. Soy is a species of legume plant which is native to East Asia. Numerous studies have examined the relationship between soy consumption, isoflavones, and breast cancer. In addition, numerous studies are exploring the benefits of soy in cell cultures $(4,5)$ and animal models $(6)$.

Soy contains genistein and daidzein isoflavones. Isoflavones are phytoestrogens, with a similarity in structure to $17-\beta$ estradiol, a hormone in human females. Isoflavones imitate the action of estrogen on organs by binding and activating estrogen receptor (7). This results in a decrease of estrogen production (7-9). This mechanism is why scientists investigate the correlation between the effects of soy and the occurrence of breast cancer. Furthermore, soy isoflavones have been shown to reduce breast cancer cell growth through estrogen receptor-independent inhibition of DNA topoisomerases and tyrosine kinases, as some other studies indicate (10-13). Moreover, genistein has anti-angiogenic and anti-inflammatory properties, and these come from the regulation of vascular endothelial growth factor and vascular endothelial growth factor receptor-2 expression (14-16). Realistically though, there is still much controversy on the matter and what effects and outcomes soy and isoflavones have in regards to breast cancer.

In a 2014 report on the subject by the American Institute for Cancer Research and the World Cancer Research Fund, which focused primarily on the effect of isoflavones intake by soy consumption on breast cancer survival rates for women patients, it was concluded that despite the limited number of published studies on the matter, there exists sufficient evidence to suggest a positive outcome. It also 
reported that higher consumption of soy and, therefore, isoflavones post-diagnosis of breast cancer is associated with a reduced death rate (17).

The purpose of this study was to carry out a detailed and up-to-date review of the literature on soy consumption with emphasis on the amount of soy and isoflavones being consumed and how that affects breast cancer risk. It was also investigated, via the literature, whether this effect applies to both pre-menopausal and post-menopausal women.

\section{Materials and Methods}

Search strategy. Due to the small number of studies on the research question, an extensive search was performed of various medical databases such as PubMed, Medline, Google Scholar, and Embase for articles that reported an association between soy, isoflavones, and breast cancer. All relevant articles up to April 2021 were included in the initial result set. The search strategy was performed according to PRISMA guidelines (18), and the PRISMA flowchart is given in Figure 1.

After reviewing the existing literature, the authors identified many reviews, prospective and retrospective studies on the benefits of soy and isoflavones in breast cancer. Despite that fact, the authors were not able to identify any systematic reviews that analyzed whether the amount of soy and isoflavones consumption played any role in the manifestation of breast cancer in general. Soy is beneficial and can reduce breast cancer risk but there was no answer on whether different amounts of consumption increase or reduce breast cancer risk. Therefore, our focus was on prospective studies that not only investigated the benefits of soy in general but provided data in regard to the amount of consumption in both pre- and postmenopausal women.

To facilitate the search query, the following terms were used: "soy", "soy isoflavones", "isoflavones", "isoflavone", "soy products", "cancer", "breast cancer", "breast cancer risk", "breast cancer survival", "breast cancer rates", "isoflavone breast cancer", "soy breast cancer", "isoflavones breast cancer", "soy isoflavones breast cancer", "soy products breast cancer", "soy products breast cancer outcome", " soy products breast cancer risk", "soy products breast cancer rate", "isoflavone breast cancer outcome", "isoflavone breast cancer risk" and "isoflavone breast cancer rate". The query utilized for returning data from the four medical databases was: ((soy OR isoflavone OR isoflavones OR (soy products) OR (soy product)) AND (breast cancer) AND (risk OR rate OR outcome OR (mortality rate))).

In an attempt to ensure all data were appropriately extracted, three Authors reviewed and assessed the results independently. The resulting set was initially checked for duplicates across the four databases, and any that were found were removed from the resulting pool accordingly. After the initial evaluation, 441 studies were identified: 349 of these were reviews and 14 were meta-analyses. An initial reading of the abstracts was performed in order to exclude any irrelevant articles that might have been included during the initial search. The remaining articles had their entire content read by the Authors. Pre-determined inclusion and exclusion criteria set at the beginning of the study were applied (see below) in order to narrow down the result set and to ensure that only relevant studies were included. Lastly, citation mining was performed on the remaining studies and the snowball procedure was applied in order

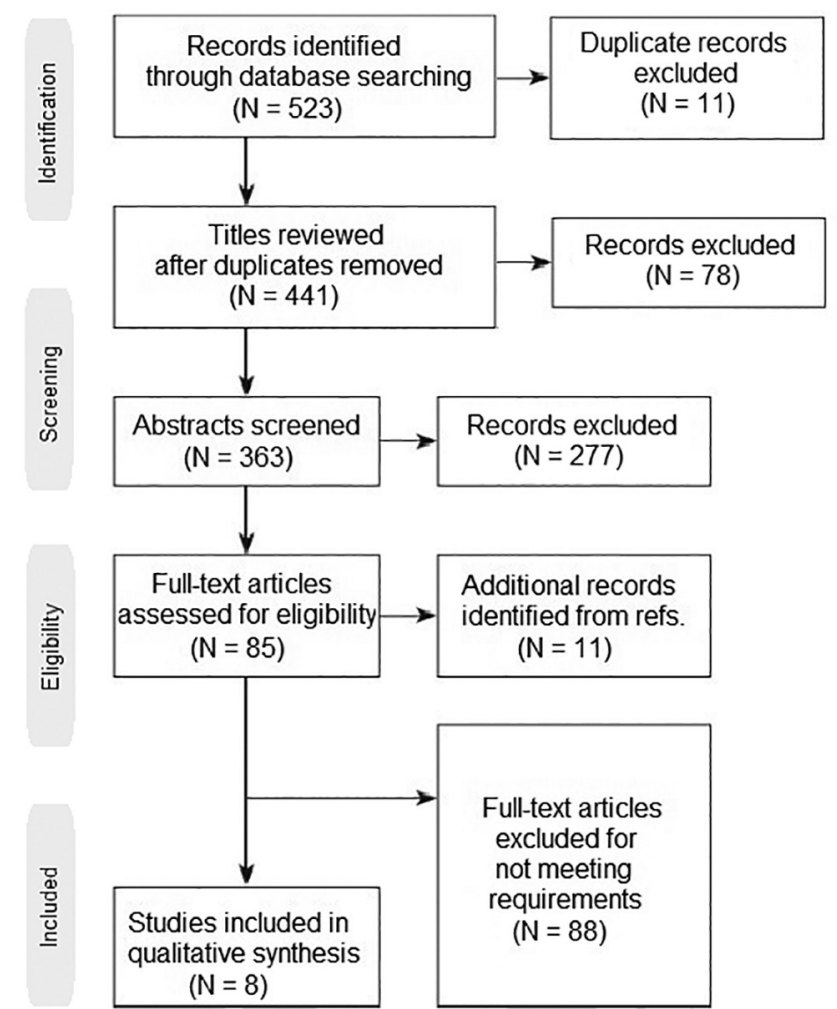

Figure 1. PRISMA flow diagram for study selection.

to identify any other related articles. When all data were extracted according to the criteria set, meaningful statistical analysis was performed on the data in order to answer the research question.

Inclusion criteria. To include only relevant studies for reviewing, the studies kept for the final pool had to be written in English, be prospective, refer to isoflavones and soy consumption and the effect they might have on breast cancer, should only refer to human populations regardless of ethnicity, have sufficient evidence on the consumption of isoflavones for an extended period of time, and report on a group that lacked consumption of isoflavones for the same period of time in order to investigate the association between the amount of intake and the end result.

Exclusion criteria. Any alternative language publications, letters and data were classified as irrelevant. Not meeting at least one inclusion criterion classified a study as non-interesting for inclusion. Cellculture studies, although of interest, were not included due to their heterogeneity in comparison to human population studies. Animal studies, case series, and case reports were also deemed irrelevant and were omitted. In the scenario of two overlapping populations, we decided only to include both if they referred to a different region topographically even if on the same country or, in the scenario where the studies overlapped in topography, population and results, only the most recent one was to be included, this was to ensure more up-to-date data were extracted. It was assumed that populations from the same geographic location would show identical results. 
Table I. Summary data from the selected studies. BC: Breast cancer.

\begin{tabular}{|c|c|c|c|c|c|c|c|c|c|c|c|}
\hline \multirow[b]{3}{*}{ Study } & \multirow[b]{3}{*}{ Country } & \multirow[b]{3}{*}{$\begin{array}{c}\text { Participants, } \\
\mathrm{n}\end{array}$} & \multicolumn{8}{|c|}{ Daily soy isoflavone consumption } & \multirow{3}{*}{$\begin{array}{c}\text { Total } \\
\text { BC } \\
\text { cases, n }\end{array}$} \\
\hline & & & \multicolumn{2}{|c|}{ BC cases, $n$} & \multicolumn{3}{|c|}{ Pre-menopausal, n } & \multicolumn{3}{|c|}{ Post-menopausal, $\mathrm{n}$} & \\
\hline & & & $\begin{array}{c}0-15 \\
\mathrm{mg} / \text { day }\end{array}$ & $\begin{array}{c}>15 \\
\text { mg/day }\end{array}$ & $\begin{array}{c}0-15 \\
\mathrm{mg} / \mathrm{day}\end{array}$ & $\begin{array}{c}>15 \\
\text { mg/day }\end{array}$ & $\mathrm{BC}$ & $\begin{array}{c}0-15 \\
\mathrm{mg} / \mathrm{day}\end{array}$ & $\begin{array}{c}>15 \\
\mathrm{mg} / \text { day }\end{array}$ & $\mathrm{BC}$ & \\
\hline $\begin{array}{l}\text { Baglia et al., } \\
2016 \text { (19) }\end{array}$ & China & 70,578 & 852 & 182 & 246 & 27 & 273 & 606 & 155 & 761 & 1,034 \\
\hline $\begin{array}{l}\text { Kang et al., } \\
2010(20)\end{array}$ & China & 524 & 132 & 392 & & & 248 & & & 276 & 524 \\
\hline $\begin{array}{l}\text { Kang et al., } \\
2012(21)\end{array}$ & China & 288 & 187 & 101 & & & 107 & & & 181 & 288 \\
\hline $\begin{array}{l}\text { Morimoto et al., } \\
2014 \text { (22) }\end{array}$ & USA & 84,550 & 3,578 & 1,191 & 507 & 150 & 657 & 3,071 & 1,041 & 4,112 & 4,769 \\
\hline $\begin{array}{l}\text { Yamamoto et al., } \\
2003 \text { (23) }\end{array}$ & Japan & 21,852 & 94 & 85 & 50 & 39 & 89 & 43 & 44 & 87 & 179 \\
\hline $\begin{array}{l}\text { Wei et al., } \\
2019(24)\end{array}$ & China & 300,852 & 2,031 & 258 & 1,004 & 116 & 1,120 & 1,027 & 142 & 1,169 & 2,289 \\
\hline $\begin{array}{l}\text { Zhang et al., } \\
2012(25)\end{array}$ & China & 616 & 397 & 219 & & & 326 & & & 290 & 616 \\
\hline $\begin{array}{l}\text { Zhang et al., } \\
2017 \text { (26) }\end{array}$ & $\begin{array}{c}\text { USA, Canada, } \\
\text { Australia }\end{array}$ & 6,235 & 4,597 & 1,524 & 2,210 & 846 & 3,056 & 2,462 & 714 & 3,176 & 6,235 \\
\hline
\end{tabular}

\section{Results}

After the evaluation, eight studies were included. All studies selected had been performed from 2003 until 2021, containing data from patients all around the world. The data reported on the amount of isoflavone consumption and risk of breast cancer diagnosed in the population. All the analyses were performed using the Review Manager 5.1 software tool (Cochrane, London, UK). A summary of the data extracted can be seen in Table I.

Statistical analysis in the eight studies was performed, trying to answer the most relevant questions in regards to soy consumption and the prevalence of breast cancer based on the amount of soy and isoflavones consumed and if they were at a pre or post-menopausal stage when diagnosed. All studies were prospective and the results were acquired by their respective authors via food frequency questionnaires. Some of the eight studies that were selected referred only to patients with breast cancer $(19,21,25)$, while others referred to the general population, including a proportion of whom which had breast cancer $(19,22-24,26)$. We deemed it necessary to include both because, despite the heterogeneity in the data, the three studies referring only to patients with breast cancer contained data which could be statistically analyzed in order to lead to an answer to our research question.

Moreover, in all eight studies, the respective authors categorized soy consumption groups in a different manner, with some having two groups of patients $(20,21,23,26)$, and even those two groups were categorized differently per study, e.g., 0-15 mg/day group compared to $>15 \mathrm{mg} /$ day group vs. 0-7 mg/day group compared to $>7 \mathrm{mg} /$ day group. Others split the study cohort into three groups, others still into three plus a control group etc. Because of all the different study designs and data included in each study being valuable for this review, we found it appropriate to extract the data and partition the groups into two sub-categories, the 'no to low consumption' (0-15 mg/day) group and the 'high consumption' (>15 mg/day) group.

For the question of whether higher dosage of soy and isoflavone consumption affected the proportion of patients diagnosed with breast cancer positively, with fewer cases being assigned to the high consumption group, the statistical analysis performed indicated a statistically significant result. Seven studies with appropriate data were used in order to perform the statistical analysis; one study was excluded in order to answer this question (26) as we were unable to make a clear distinction for the $5-15 \mathrm{mg}$ /day consumption group and it was not possible to extract the data appropriately to provide an accurate result. As can be seen in Figure 2, the proportion of women diagnosed with breast cancer in the 0 to $15 \mathrm{mg} /$ day group was significantly higher $(p<0.000001)$ when compared to the group that consumed more than 15 $\mathrm{mg} /$ day of soy isoflavones. From the total number of breast cancer cases, $75 \%$ (7,271 patients) belonged to the $0-15$ $\mathrm{mg} /$ day group, while only a mere $25 \%$ (2,428 patients) belonged to the group consuming $>15 \mathrm{mg} /$ day.

For the question of whether the amount of soy consumed by the participants played a vital role in the manifestation of breast 


\begin{tabular}{|c|c|c|c|c|c|c|c|c|c|c|c|c|}
\hline Study or Subgroup & \multicolumn{2}{|c|}{$0-15 \mathrm{mg} / \mathrm{day}$} & \multicolumn{2}{|c|}{$>15 \mathrm{mg} / \mathrm{day}$} & Weight & Odds Ratio & \multicolumn{6}{|c|}{$\begin{array}{c}\text { Odds Ratio } \\
\text { M-H, Fixed, 95\% Cl }\end{array}$} \\
\hline Baglia et al. 2016 (19) & 852 & 1034 & 182 & 1034 & $4.0 \%$ & $21.91[17.48,27.48]$ & & & & & $\rightarrow$ & \\
\hline Kang et al. $2010(20)$ & 132 & 524 & 392 & 524 & $36.4 \%$ & $0.11[0.09,0.15]$ & & - & & & & \\
\hline Kang et al. 2012 (21) & 187 & 288 & 101 & 288 & $4.4 \%$ & $3.43[2.43,4.83]$ & & & $\rightarrow$ & & & \\
\hline Morimoto et al. 2014 (22) & 3578 & 4769 & 1191 & 4769 & $36.9 \%$ & $9.03[8.23,9.90]$ & & & & घ & & \\
\hline Wei et al. 2019 (23) & 2031 & 2289 & 258 & 2289 & $3.6 \%$ & $61.97[51.60,74.43]$ & & & & & & $\rightarrow$ \\
\hline Yamamoto et al. 2003 (24) & 94 & 179 & 85 & 179 & $5.0 \%$ & $1.22[0.81,1.85]$ & & & & & & \\
\hline Zhang et al. 2012 (25) & 397 & 616 & 219 & 616 & $9.7 \%$ & $3.29[2.60,4.15]$ & & & $\rightarrow$ & & & \\
\hline Total $(95 \% \mathrm{Cl})$ & & 9699 & & 9699 & $100.0 \%$ & $7.01[6.58,7.47]$ & & & & 1 & & \\
\hline Total events & 7271 & & 2428 & & & & & & & & & \\
\hline $\begin{array}{l}\text { Heterogeneity: } \mathrm{Chi}^{2}=1634 \text {. } \\
\text { Test for overall effect: } Z=5\end{array}$ & $\begin{array}{l}1, d f=6( \\
8(p<0 .\end{array}$ & $\begin{array}{l}0.00 \\
0001)\end{array}$ & $001) ;\left.\right|^{2}=$ & $100 \%$ & & & 0.01 & $\begin{array}{c}0.1 \\
\text { Favours [0-1 }\end{array}$ & avours [? & $\begin{array}{c}10 \\
15 \mathrm{mg}\end{array}$ & /day] & 100 \\
\hline
\end{tabular}

Figure 2. Forest plot of the prevalence of breast cancer in women in selected studies based on the amount of isoflavones they consumed. CI: Confidence interval.

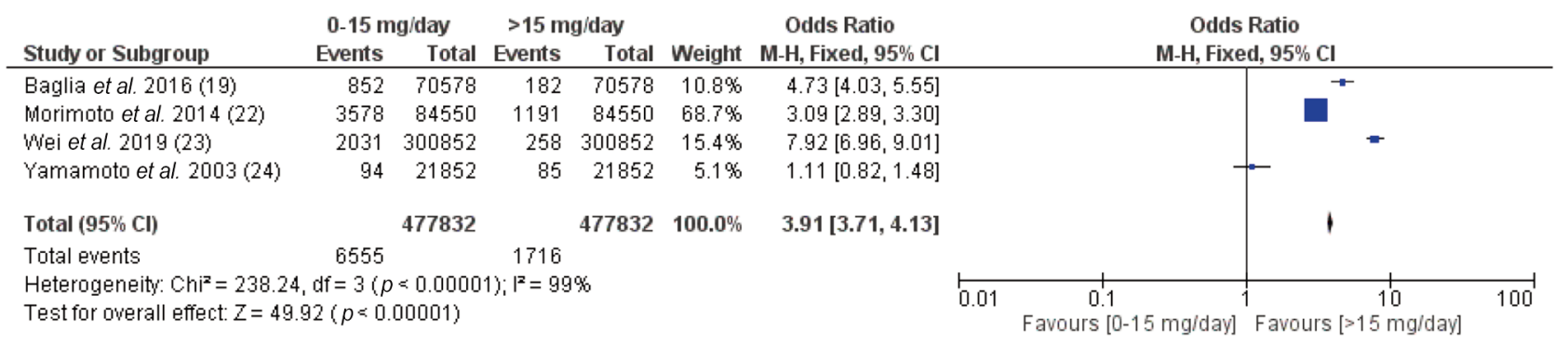

Figure 3. Forest plot on the prevalence of breast cancer in the total study populations based on the amount of isoflavones they consumed. CI: Confidence interval.

cancer when compared to the total population of the studies, the statistical analysis performed indicated a statistically significant result $(p<0.00001)$. Four studies with appropriate data were used. As Figure 3 indicates, the proportion of women belonging to the no-to-low consumption group and diagnosed with breast cancer was $1.37 \%$ of the total population $(6,555$ patients) and was almost fourfold the proportion of women belonging to the high consumption group $(0.35 \%, 1,716$ patients). Figure 3 also shows that only a small percentage of participants, of both high and low consumption groups, were diagnosed with breast cancer, a mere $1.73 \%$ (8,271 patients) out of the entire population (477,832 women).

Menopausal stage can affect breast cancer (30). In order to further investigate whether the level of soy and isoflavone consumption can affect breast cancer occurrence, we performed a statistical analysis on different levels of soy intake for pre-menopausal and post-menopausal women separately, utilizing the data of five studies that supported such an analysis $(20,22-24,26)$. Figure 4 demonstrates that the amount of soy isoflavone consumption for premenopausal women can indeed significantly influence the risk of breast cancer in the population. Out of the total of 5,195 pre-menopausal women with breast cancer, $77.3 \%$ $(4,017)$ consumed $0-15 \mathrm{mg} /$ day of soy and isoflavones and were diagnosed with breast cancer, while only $22.7 \%(1,178)$ consumed more than $15 \mathrm{mg} /$ day and were diagnosed with breast cancer $(p<0.0001)$.

The results followed a similar pattern for women in their post-menopausal period $(p<0.00001)$. As can be seen in Figure 5, the proportion of breast cancer cases for women that had high soy isoflavone consumption in their postmenopausal stage was less than their counterparts with lower consumption. Out of the total of 9,305 breast cancer cases diagnosed in these five studies, $77.5 \%(7,209)$ diagnosed with breast cancer belonged to the $0-15 \mathrm{mg} /$ day group, while only $22.5 \%$ (2,096 patients) belonged to the $>15 \mathrm{mg} /$ day group.

\section{Discussion}

There were several attempts by scientists to determine the effect of daily dietary soy intake on breast cancer incidence in women with risk factors or no previous history. In some of the studies $(20,21,23,25)$, the models were adjusted in order to take into consideration common risk factors associated with breast cancer. Common risk factors include: age, earlier age at menarche, age at diagnosis, estrogen receptor/progesterone receptor status, smoking, alcohol consumption, menopausal status, use of tamoxifen, education level, high fat and meat 


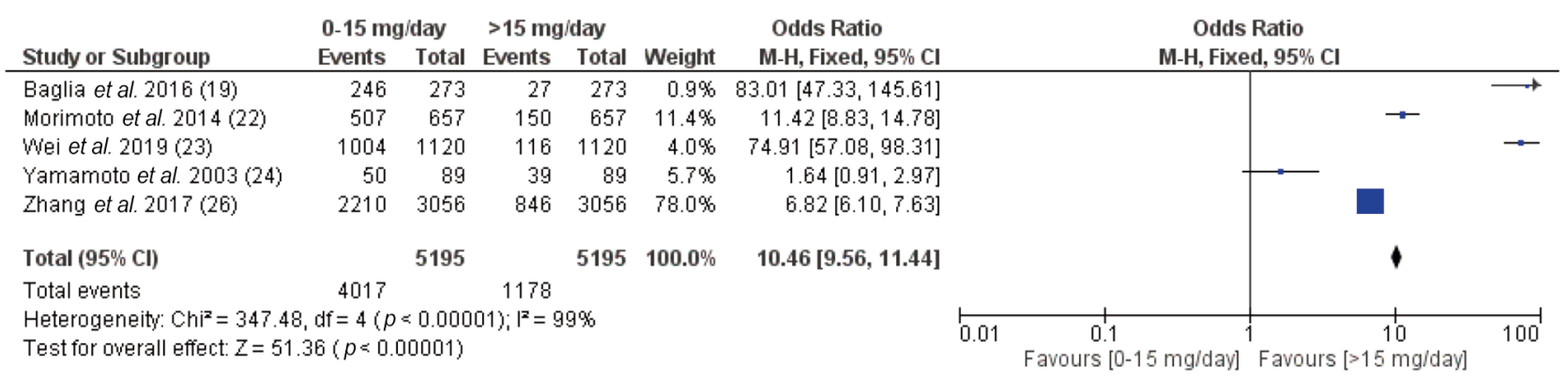

Figure 4. Breast cancer cases based on soy isoflavone consumption for pre-menopausal women in selected studies. CI: Confidence interval.

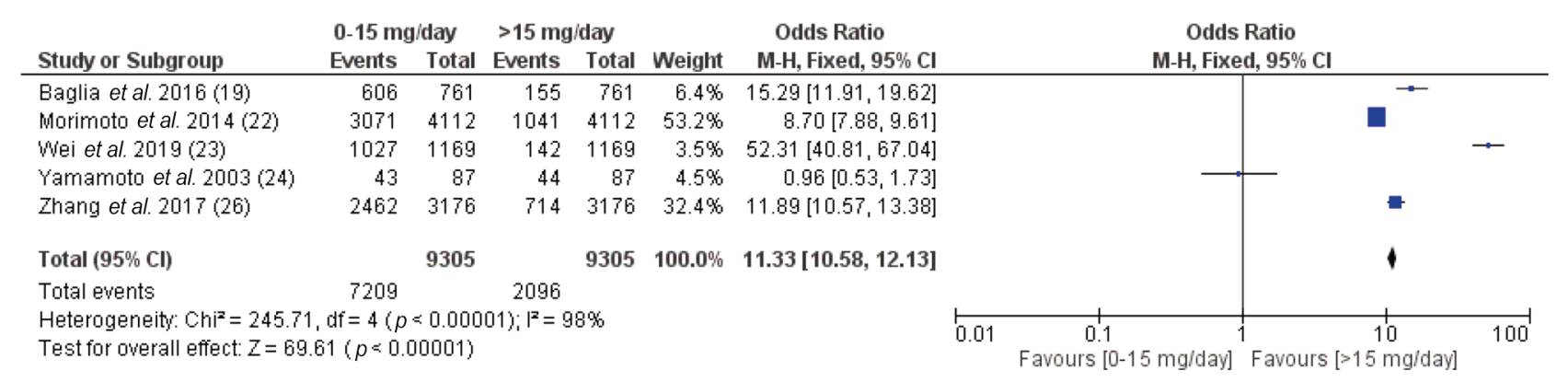

Figure 5. Breast cancer cases based on soy isoflavone consumption for post-menopausal women in selected studies. CI: Confidence interval.

consumption, body mass index, family history of cancer, radiotherapy, chemotherapy, and endocrine therapy (34). Findings from all eight prospective studies on soy and breast cancer association that were included in this review were inconsistent, which may be due to different levels of soy intake across the various studies, heterogeneity of the data, and the different characteristics of the examined populations. Cohort studies conducted among women with low (27-29) $(<5$ $\mathrm{mg}$ /day) or moderate $(20-30 \mathrm{mg} /$ day $)$ dietary intake $(22,30)$ of soy isoflavones did not demonstrate a clear association between breast cancer risk and soy intake.

Among the studies that reported moderate soy consumption, three agree with the conclusion that there is no correlation between daily consumption and the risk of breast cancer $(22,24,30)$. Nishio et al. found no significant association between consumption of soy products and breast cancer risk (30), while Morimoto et al. mentioned that in the Japanese American, Native Hawaiian or Latina population subgroups in which the median isoflavone intake was higher than other ethnic groups, they did not find a statistically significant association between high absolute isoflavone intake and overall breast cancer risk (22). In a study performed by Wei et al. in over 300,000 women across China, the dose-response meta-analysis that was performed on the data failed to reject the linearity assumption between breast cancer risk and soy isoflavone intake (24).
In two of the studies in which the amount of intake was compared between more than two groups $(19,23)$, it was found that there was a reduced breast cancer risk for the group with the highest soy consumption when compared to women of the lowest consumption group. Baglia et al. reported that high soy intake during adolescence and adulthood was associated with reduced pre-menopausal breast cancer risk [hazard ratio $=0.53,95 \%$ confidence interval $(\mathrm{CI})=0.32-0.88$ ] (19). Similarly, Yamamoto et al. found statistically significant inverse associations between consumption of miso soup and isoflavones in general and breast cancer risk (23). When comparing with women in the lowest quartile of their population pool, higher consumption quartiles had adjusted relative risk of breast cancer of 0.76 (95\% $\mathrm{CI}=0.47$ to 1.2$)$, 0.90 (95\% CI=0.56 to 1.5$)$ and 0.46 (95\% $\mathrm{CI}=0.25$ to 0.84$)$.

Accordingly, in our own statistical analysis of the data combined from these eight studies, all comparisons were of great significance and showed a favorable outcome for the group with high soy and isoflavone consumption (>15 $\mathrm{mg} /$ day) when compared to the low consumption group (0$15 \mathrm{mg} /$ day) in all questions the authors attempted to answer via statistical analysis. Initially, out of the 9,699 patients that were diagnosed with breast cancer in seven of the studies (19-25), only a quarter (25\%) belonged to the high consumption group, with most belonging to the group that consumed none or up to $15 \mathrm{mg} /$ day of soy and isoflavones. 
The odds ratio (OR) of $7.01(95 \% \mathrm{CI}=6.58-7.47)$ in the forest plot of Figure 2 clearly shows consumption of $>15$ $\mathrm{mg} /$ day is favored when compared to $0-15 \mathrm{mg} /$ day. Interestingly, in the four studies that examined soy consumption in the general population $(19,22-24)$, a very low proportion were diagnosed with breast cancer $(1.73 \%)$ despite their menopausal stage and again only a fraction belonged to the high consumption group $(0.35 \%$ for $>15$ $\mathrm{mg} /$ day as opposed to $1.37 \%$ for $0-15 \mathrm{mg} /$ day), with an OR of 3.91 (95\% CI=3.71 to 4.13 ) supporting the favorable effect of high soy consumption.

During the data extraction, a clear distinction between preand post-menopausal patients with breast cancer was made by all authors (19-26). Being aware that menopausal stage is a risk factor for breast cancer occurrence allowed us to investigate further how beneficial the amount of soy consumption is, excluding menopausal stage as a risk factor. In our two analyses performed separately on pre-and postmenopausal women, the findings were quite interesting. Of pre-menopausal patients with breast cancer, only $22.7 \%$ consumed more than $15 \mathrm{mg} /$ day of soy and isoflavones while the remaining $77.3 \%$ consumed none or up to $15 \mathrm{mg} /$ day. This finding reflected the favorable association of higher consumption with fewer cases in the whole patient population $(\mathrm{OR}=10.46,95 \% \mathrm{CI}=9.56-11.44)$. The higher the consumption of soy/soy isoflavones, the lower the proportion of patients with breast cancer. As expected, a similar result was shown from the data analysis of post-menopausal patients with breast cancer $(\mathrm{OR}=11.33,95 \% \mathrm{CI}=10.58-12.13)$, with $77.5 \%$ of the cases belonging to the $0-15 \mathrm{mg} /$ day group.

\section{Conclusion}

Some studies in the past attempted to correlate the consumption of soy isoflavones and breast cancer, whether that was recurrence or first diagnosis. Most of these studies were inconclusive, and some of them showed a statistically significant result only for post-menopausal women. The most recent systematic review performed on the subject was completed 6 years ago. Since then, a variety of new studies were conducted across the globe. In this study, we have concluded that soy consumption and, therefore, isoflavone intake is beneficial for breast cancer prognosis and lowers breast cancer manifestation. Women with high soy and isoflavone consumption have a lower risk of being diagnosed with breast cancer when compared to women that do not have soy in their dietary plan. Scientists should continue investigating soy and its beneficial properties and hopefully use it appropriately to minimize the risk of breast cancer manifestation.

\section{Conflicts of Interest}

The Authors declare no conflicts of interest.

\section{Authors' Contributions}

I. Boutas: Conceptualization, methodology, data curation, writing, original draft preparation. A. Kontogeorgi: Methodology, data curation, writing, original draft preparation, software. C. Dimitrakakis: Supervision, writing, reviewing and editing. S. Kalantaridou: Supervision, writing, reviewing and editing.

\section{References}

1 National Cancer Institute 2021: Breast Cancer - Patient Version. Available at https://www.cancer.gov/types/breast [Last accessed on November $12^{\text {th }}, 2021$ ]

2 Bandera EV, King M, Chandran U, Paddock LE, RodriguezRodriguez L and Olson SH: Phytoestrogen consumption from foods and supplements and epithelial ovarian cancer risk: a population-based case control study. BMC Womens Health 11: 40, 2011. PMID: 21943063. DOI: 10.1186/1472-6874-11-40

3 Barnes S, Prasain J, D'Alessandro T, Arabshahi A, Botting N, Lila MA, Jackson G, Janle EM and Weaver CM: The metabolism and analysis of isoflavones and other dietary polyphenols in foods and biological systems. Food Funct 2(5): 235-244, 2011. PMID: 21779561. DOI: 10.1039/c1fo10025d

4 Yang S, Zhou Q and Yang X: Caspase-3 status is a determinant of the differential responses to genistein between MDA-MB-231 and MCF-7 breast cancer cells. Biochim Biophys Acta 1773(6): 903911, 2007. PMID: 17490757. DOI: 10.1016/j.bbamcr.2007.03.021

5 Hatono M, Ikeda H, Suzuki Y, Kajiwara Y, Kawada K, Tsukioki T, Kochi M, Suzawa K, Iwamoto T, Yamamoto H, Shien T, Yamane M, Taira N, Doihara $\mathrm{H}$ and Toyooka S: Effect of isoflavones on breast cancer cell development and their impact on breast cancer treatments. Breast Cancer Res Treat 185(2): 307316, 2021. PMID: 33034801. DOI: 10.1007/s 10549-020-05957-Z

6 Setchell KD, Brown NM, Zhao X, Lindley SL, Heubi JE, King $\mathrm{EC}$ and Messina MJ: Soy isoflavone phase II metabolism differs between rodents and humans: implications for the effect on breast cancer risk. Am J Clin Nutr 94(5): 1284-1294, 2011. PMID: 21955647. DOI: 10.3945/ajen.111.019638

7 Ziaei S and Halaby R: Dietary isoflavones and breast cancer risk. Medicines (Basel) 4(2): 18, 2017. PMID: 28930233. DOI: 10.3390/medicines4020018

8 Fritz H, Seely D, Flower G, Skidmore B, Fernandes R, Vadeboncoeur S, Kennedy D, Cooley K, Wong R, Sagar S, Sabri $\mathrm{E}$ and Fergusson D: Soy, red clover, and isoflavones and breast cancer: a systematic review. PLoS One 8(11): e81968, 2013. PMID: 24312387. DOI: 10.1371/journal.pone.0081968

9 Chen M, Rao Y, Zheng Y, Wei S, Li Y, Guo T and Yin P: Association between soy isoflavone intake and breast cancer risk for pre- and post-menopausal women: a meta-analysis of epidemiological studies. PLoS One 9(2): e89288, 2014. PMID: 24586662. DOI: 10.1371/journal.pone.0089288

10 Hirano T, Oka K and Akiba M: Antiproliferative effects of synthetic and naturally occurring flavonoids on tumor cells of the human breast carcinoma cell line, ZR-75-1. Res Commun Chem Pathol Pharmacol 64(1): 69-78, 1989. PMID: 2749004.

11 Pagliacci MC, Smacchia M, Migliorati G, Grignani F, Riccardi $\mathrm{C}$ and Nicoletti I: Growth-inhibitory effects of the natural phytooestrogen genistein in MCF-7 human breast cancer cells. Eur J Cancer 30A(11): 1675-1682, 1994. PMID: 7833143. DOI: 10.1016/0959-8049(94)00262-4 
12 Kuriu A, Ikeda H, Kanakura Y, Griffin JD, Druker B, Yagura H, Kitayama H, Ishikawa J, Nishiura $\mathrm{T}$ and Kanayama Y: Proliferation of human myeloid leukemia cell line associated with the tyrosine-phosphorylation and activation of the proto-oncogene c-kit product. Blood 78(11): 2834-2840, 1991. PMID: 1720036.

13 Cunningham BD, Threadgill MD, Groundwater PW, Dale IL and Hickman JA: Synthesis and biological evaluation of a series of flavones designed as inhibitors of protein tyrosine kinases. Anticancer Drug Des 7(5): 365-384, 1992. PMID: 1388629.

14 Buteau-Lozano H, Velasco G, Cristofari M, Balaguer P and Perrot-Applanat $\mathrm{M}$ : Xenoestrogens modulate vascular endothelial growth factor secretion in breast cancer cells through an estrogen receptor-dependent mechanism. J Endocrinol 196(2): 399-412, 2008. PMID: 18252963. DOI: 10.1677/JOE-07-0198

15 Guo Y, Wang S, Hoot DR and Clinton SK: Suppression of VEGF-mediated autocrine and paracrine interactions between prostate cancer cells and vascular endothelial cells by soy isoflavones. J Nutr Biochem 18(6): 408-417, 2007. PMID: 17142033. DOI: $10.1016 /$ j.jnutbio.2006.08.006

16 Farina HG, Pomies M, Alonso DF and Gomez DE: Antitumor and antiangiogenic activity of soy isoflavone genistein in mouse models of melanoma and breast cancer. Oncol Rep 16(4): 885891, 2006. PMID: 16969510.

17 World Cancer Research Fund International/American Institute for Cancer Research: Continuous update project report: Diet, nutrition, physical activity, and breast cancer survivors 2014 . Available at https://www.wcrf.org/wp-content/uploads/2021/ 03/Breast-Cancer-Survivors-2014-Report.pdf [Last accessed on November $\left.12^{\text {th }}, 2021\right]$

18 PRISMA - Transparent reporting of systematic reviews and meta-analyses. PRISMA 2020 Checklist. Available at: http://www.prisma-statement.org/documents/PRISMA_2020_ checklist.docx [Last accessed on November 12 $2^{\text {th }}, 2021$ ]

19 Baglia ML, Zheng W, Li H, Yang G, Gao J, Gao YT and Shu $\mathrm{XO}$ : The association of soy food consumption with the risk of subtype of breast cancers defined by hormone receptor and HER2 status. Int J Cancer 139(4): 742-748, 2016. PMID: 27038352. DOI: $10.1002 / \mathrm{ijc} .30117$

20 Kang X, Zhang Q, Wang S, Huang X and Jin S: Effect of soy isoflavones on breast cancer recurrence and death for patients receiving adjuvant endocrine therapy. CMAJ 182(17): 18571862, 2010. PMID: 20956506. DOI: 10.1503/cmaj.091298

21 Kang HB, Zhang YF, Yang JD and Lu KL: Study on soy isoflavone consumption and risk of breast cancer and survival. Asian Pac J Cancer Prev 13(3): 995-998, 2012. PMID: 22631686. DOI: 10.7314/apjcp.2012.13.3.995

22 Morimoto Y, Maskarinec G, Park SY, Ettienne R, Matsuno RK, Long C, Steffen AD, Henderson BE, Kolonel LN, Le Marchand $\mathrm{L}$ and Wilkens LR: Dietary isoflavone intake is not statistically significantly associated with breast cancer risk in the Multiethnic Cohort. Br J Nutr 112(6): 976-983, 2014. PMID: 25201305. DOI: $10.1017 / \mathrm{S} 0007114514001780$

23 Yamamoto S, Sobue T, Kobayashi M, Sasaki S, Tsugane S and Japan Public Health Center-Based Prospective Study on Cancer Cardiovascular Diseases Group: Soy, isoflavones, and breast cancer risk in Japan. J Natl Cancer Inst 95(12): 906-913, 2003. PMID: 12813174. DOI: 10.1093/jnci/95.12.906

24 Wei Y, Lv J, Guo Y, Bian Z, Gao M, Du H, Yang L, Chen Y, Zhang X, Wang T, Chen J, Chen Z, Yu C, Huo D, Li L and China Kadoorie Biobank Collaborative Group: Soy intake and breast cancer risk: a prospective study of 300,000 Chinese women and a dose-response meta-analysis. Eur J Epidemiol 35(6): 567-578, 2020. PMID: 31754945. DOI: 10.1007/s10654-019-00585-4

25 Zhang YF, Kang HB, Li BL and Zhang RM: Positive effects of soy isoflavone food on survival of breast cancer patients in China. Asian Pac J Cancer Prev 13(2): 479-482, 2012. PMID: 22524810. DOI: 10.7314/apjcp.2012.13.2.479

26 Zhang FF, Haslam DE, Terry MB, Knight JA, Andrulis IL, Daly MB, Buys SS and John EM: Dietary isoflavone intake and allcause mortality in breast cancer survivors: The Breast Cancer Family Registry. Cancer 123(11): 2070-2079, 2017. PMID: 28263368. DOI: $10.1002 /$ cncr.30615

27 Horn-Ross PL, Hoggatt KJ, West DW, Krone MR, Stewart SL, Anton H, Bernstei CL, Deapen D, Peel D, Pinder R, Reynolds P, Ross RK, Wright $\mathrm{W}$ and Ziogas A: Recent diet and breast cancer risk: the California Teachers Study (USA). Cancer Causes Control 13(5): 407-415, 2002. PMID: 12146845. DOI: 10.1023/ a:1015786030864

28 Touillaud MS, Thiébaut AC, Niravong M, Boutron-Ruault MC and Clavel-Chapelon F: No association between dietary phytoestrogens and risk of premenopausal breast cancer in a French cohort study. Cancer Epidemiol Biomarkers Prev 15(12): 2574-2576, 2006. PMID: 17164390. DOI: 10.1158/10559965.EPI-06-0543

29 Hedelin M, Löf M, Olsson M, Adlercreutz H, Sandin S and Weiderpass E: Dietary phytoestrogens are not associated with risk of overall breast cancer but diets rich in coumestrol are inversely associated with risk of estrogen receptor and progesterone receptor negative breast tumors in Swedish women. J Nutr 138(5): 938-945, 2008. PMID: 18424605. DOI: 10.1093/ jn/138.5.938

30 Nishio K, Niwa Y, Toyoshima H, Tamakoshi K, Kondo T, Yatsuya H, Yamamoto A, Suzuki S, Tokudome S, Lin Y, Wakai $\mathrm{K}$, Hamajima $\mathrm{N}$ and Tamakoshi A: Consumption of soy foods and the risk of breast cancer: findings from the Japan Collaborative Cohort (JACC) Study. Cancer Causes Control 18(8): 801-808, 2007. PMID: 17619154. DOI: 10.1007/s10552007-9023-7

31 Allred CD, Allred KF, Ju YH, Virant SM and Helferich WG: Soy diets containing varying amounts of genistein stimulate growth of estrogen-dependent (MCF-7) tumors in a dosedependent manner. Cancer Res 61(13): 5045-5050, 2001. PMID: 11431339.

$32 \mathrm{Ju}$ YH, Doerge DR, Allred KF, Allred CD and Helferich WG: Dietary genistein negates the inhibitory effect of tamoxifen on growth of estrogen-dependent human breast cancer (MCF-7) cells implanted in athymic mice. Cancer Res 62(9): 2474-2477, 2002. PMID: 11980635.

33 Varinska L, Gal P, Mojzisova G, Mirossay L and Mojzis J: Soy and breast cancer: focus on angiogenesis. Int J Mol Sci 16(5): 11728-11749, 2015. PMID: 26006245. DOI: 10.3390/ ijms 160511728

34 McPherson K, Steel CM and Dixon JM: ABC of breast diseases. Breast cancer-epidemiology, risk factors, and genetics. BMJ 321(7261): 624-628, 2000. PMID: 10977847. DOI: 10.1136/ bmj.321.7261.624

Received September 24, 2021

Revised November 13, 2021

Accepted November 18, 2021 